\title{
Energy Efficiency of Short-Term Natural Room Ventilation
}

\author{
Andrii Zakovorotnyi ${ }^{1}$, Olga Tadlia ${ }^{2}$, Pavel Krukovsky ${ }^{3}$, \\ ${ }^{1,2,3}$ National Academy of Science of Ukraine
}

\begin{abstract}
A comparison of natural trickle ventilation with a constantly opened window, forming a small vent opening, versus short-term ventilation performed by a briefly wide opened window has been made using CFD. It is shown that the value of energy efficiency of the short-term ventilation can be both positive and negative depending on the intensity and frequency of its realization. The nomogram of energy efficient usage of the periodic short-term ventilation has been developed on the results of physical experiment.
\end{abstract}

Keywords - Short-term ventilation, trickle ventilation, room thermal state, energy efficiency, CFD modeling.

\section{INTRODUCTION}

To save energy consumed by the heating system of the building it is important not only to improve thermal insulation of the building envelope (walls, attic and basement floors), to replace windows, etc., but also to decrease heat losses associated with ventilation.

In such situations mechanical ventilation based on heat exchanger or heat pump is usually used [1]. However, such systems are quite expensive and their implementation is associated with partial or complete renovation of the building, which in many cases is impossible. Hence, in old buildings with poor mechanical ventilation some energy savings should be achieved through the proper organization of natural ventilation.

In general, natural ventilation can be performed using two methods: trickle ventilation with a constantly slightly opened window (pane) and periodic short-term ventilation performed by a briefly widely opened window. An interest is the comparison of energy efficiency of these two types, which provide equal air exchange rate (the value showing how many times in one hour indoor air is completely replaced by the new one) in both cases. The lowest boundary of the air exchange rate for the current room is determined by sanitary limits. In [2] it was noted that the short-term ventilation provides improved hygiene standards in comparison with trickle ventilation due to the fact that during short-term ventilation no mold is formed on the inner surfaces of the building envelope. Because these surfaces do not have enough time to be cooled during ventilation, moisture condensation is avoided. The authors of [3] have performed detailed experimental studies of short-term ventilation. The results showed that to ensure human comfort, ventilation should be performed during relatively short period of time with sufficiently high frequency. However, they did not conduct analysis of energy efficiency of the mentioned methods of ventilation. In paper [4], numerical calculation showed that trickle ventilation increases heat losses with air exchange up to 20 times in comparison with short-term ventilation. Unfortunately, the calculations made by the authors [4] have been made on unfair assumptions and are wrong. Consequently, the results of the mentioned articles have to be checked and energy efficiency of the proposed methods of ventilation has to be investigated.

\section{THE AIM OF RESEARCH}

The aim of the present work is to conduct a comparative analysis of the short-term and trickle ventilation in terms of energy efficiency using numerical and physical experiments and to provide recommendations for the considerable usage of natural ventilation. The value of energy efficiency $\eta$ of the short-term ventilation relatively to trickle ventilation will be determined using the following expression:

$$
\eta=\frac{Q_{\text {trickle }}-Q_{\text {short-term }}}{Q_{\text {trickle }}} \cdot 100 \%,
$$

where $Q_{\text {trickle }}, Q_{\text {short-term }}$ are the amounts of heat which are needed for the room heating during short-term and trickle ventilation respectively. The value $\eta$ of the ventilation is a consequence of the action of the following simultaneous factors:

- during the short-term ventilation the reduction of the room temperature leads to the decreasing of temperature difference between the room and the environment. Consequently, heat losses are reduced;

- during the short-term ventilation outside air cools the internal walls and furniture in the room, so additional thermal energy for heating is needed;

- if the short-term ventilation is performed with great frequency, the heated by the radiator hot air goes out of the room into the environment and does not have time to give heat to the cooled room walls and furniture.

The authors suggest that the value $\eta$ can have both positive and negative meaning depending on the execution time, frequency and intensity of short-term ventilation and the power of the heater. 


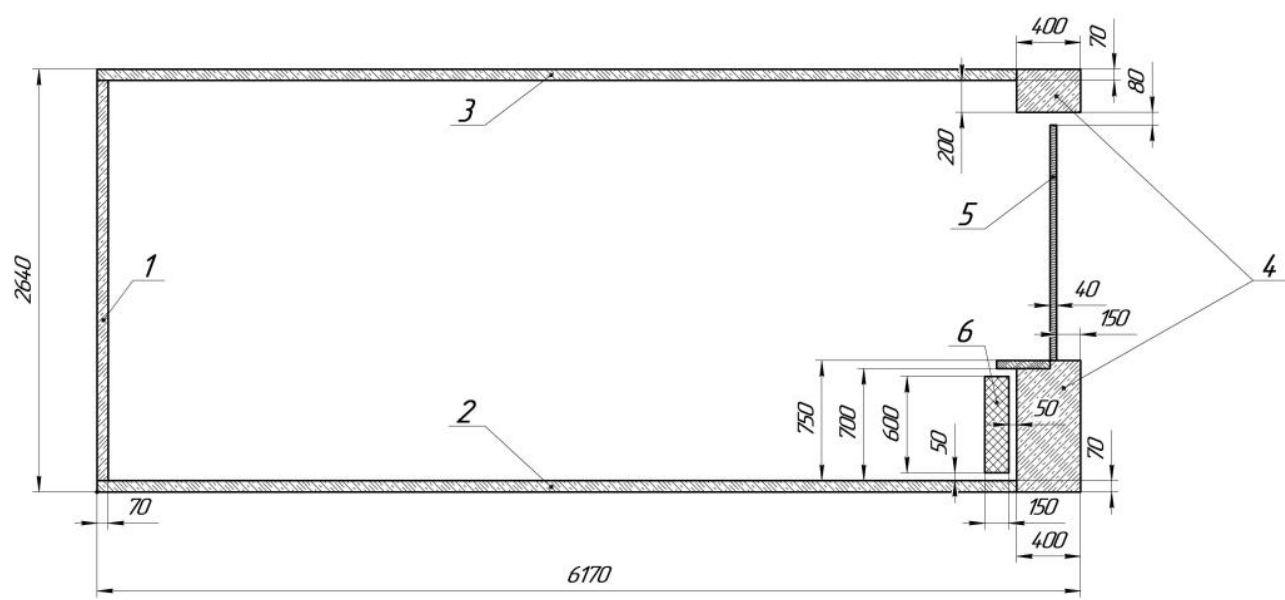

Fig. 1. Two-dimensional room space model. 1 - inner wall of the room, 2 - floor, 3 - ceiling, 4 - parts of the outer wall, 5 - window, 6 - radiator

\section{CFD SIMULATION}

To quantify the value of $\eta$, CFD simulation of room ventilation was made using the Ansys Fluent software package.

Since only integrated energy characteristics of the room (the amount of heat consumed by the heater during the execution of the discussed ventilation methods) are of interest, it is sufficient to consider a two-dimensional task (see Fig. 1). The room has geometric dimensions of $6,170 \cdot 2,640 \mathrm{~mm}$. The room temperature is monitored with temperature sensor located in the center of the model space and maintained at level of $20 \pm 0.5^{\circ} \mathrm{C}$ by the radiator [5]. Ambient temperature is $0{ }^{\circ} \mathrm{C}$. The air is assumed to be an ideal incompressible gas and according to this the air density in this case depends only on the temperature. Thermal properties of materials do not depend on temperature and are given by [6].

On the outer surfaces of the floor, ceiling, and interior wall adiabatic conditions are set. For the outer surfaces of the window and exterior wall the convection boundary conditions are applied.

Number of mesh cells amounts to 96,000 .

A mathematical model of the room's thermal state is described with the momentum conservation equation, the continuity equation and energy equation. The results of [3] on air exchange rate investigation during short-term ventilation were used for the verification of turbulence model that encloses the system of differential equations. For this task, an individual three-dimensional model was developed to obtain detailed results. In Fig. 2, the comparison of turbulent models is shown. For this figure normalized time and temperature are used:

$$
\begin{gathered}
\tau^{*}=\frac{\tau}{\Delta \tau *}, \\
t^{*}\left(\tau^{*}\right)=\frac{t_{r}\left(\tau^{*}\right)-t_{a m b}}{t_{r}(0)-t_{a m b}},
\end{gathered}
$$

where $\tau$ is the real time of experiment, $\Delta \tau *$ is the duration of time needed to change all the volume of indoor air with the ambient air, $t_{a m b}$ - ambient temperature, $t_{r}\left(\tau^{*}\right)$ - mean air room temperature as a function of normalized time.

From the Fig. 2 it can be concluded that the best twoequation model for the modeling of short-term ventilation is Menter's Shear Stress Transport model of turbulence.

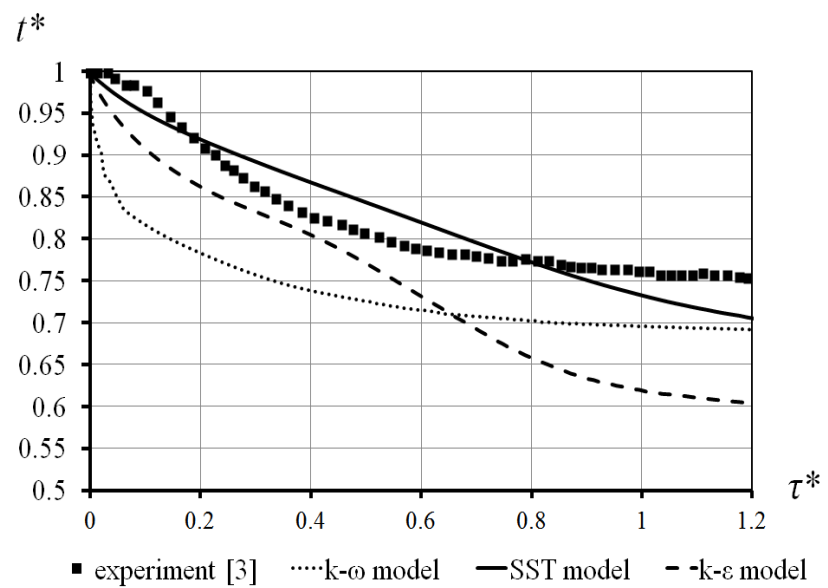

Fig. 2. The verification of turbulance model for the calculation of short-term natural ventilation. $t^{*}$ - normalized mean air room temperature.

For the modeling of the short-term ventilation, air exchange between the room and environment is provided by the presence of vent opening between the window and the outer wall of the height $h=80 \mathrm{~mm}$ with the applied linear pressure distribution law as the boundary condition. This height of the vent opening allows obtaining an air exchange rate equal to 1 volume of room air per hour during constant trickle ventilation. The vent opening is situated at height of $2 \mathrm{~m}$ above the floor.

It was calculated that for the steady-state solution during trickle ventilation $300 \mathrm{~W}$ of heat capacity is needed.

For the simulation of the short-term ventilation, two periods of time are considered:

1) $\tau_{\text {closed }}$ - period of time during which the vent opening between the room and the environment is closed and there is a closed circulation of air in a room. 


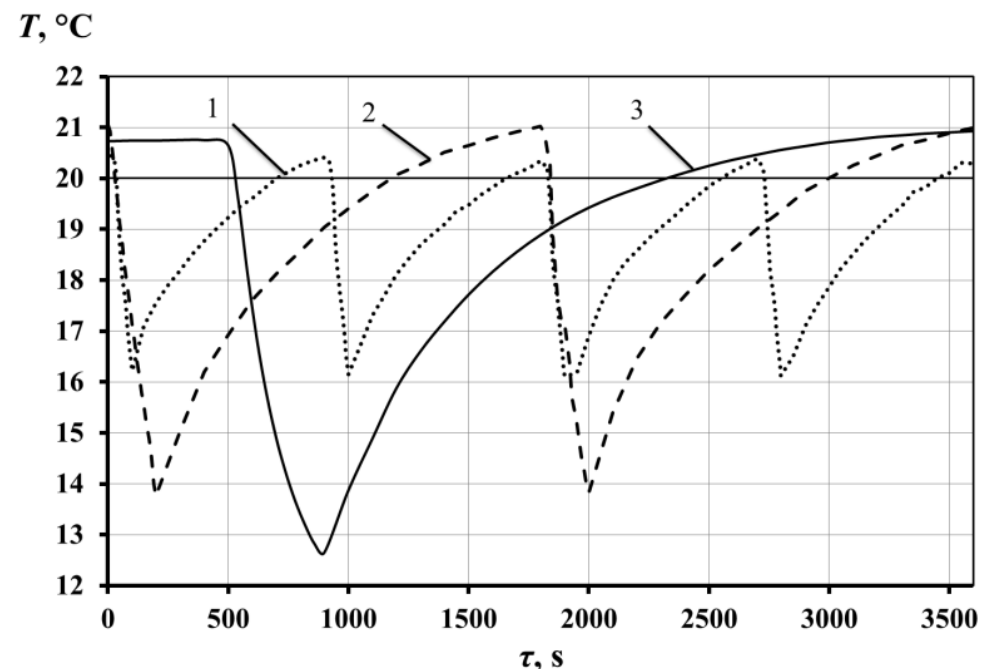

Fig. 3. Time dependence of the room air temperature of short-term ventilation options № 1 - 3 .

2) $\tau_{\text {opened }}$ - period of time during which the vent opening between the room and the environment is opened.

The height of vent opening in this case is $200 \mathrm{~mm}$.

Periods of time $\tau_{\text {closed }}$ and $\tau_{\text {opened }}$ selected in such a way that the integral air exchange rate is the same for all variants of calculation and equals to 1 volume of indoor air per hour. The summary of $\tau_{\text {closed }}$ and $\tau_{\text {opened }}$ defines one short-term ventilation cycle.

In Table 1 input and output data for the calculation variants are shown: values of $\tau_{\text {closed }}$ and $\tau_{\text {opened }}$, number of ventilation cycles per hour $N_{\text {cycles }}$, heating capacity of the radiator $N_{\text {rad }}$ and calculated values of variable $\eta$.

TABLE I

INPUT AND OUTPUT DATA OF CFD-CALCULATION TASK

\begin{tabular}{|c|c|c|c|c|c|c|}
\hline № & $\begin{array}{c}N_{\text {rad, }}, \\
\mathrm{W}\end{array}$ & $\begin{array}{c}N_{\text {rad }} N_{\text {steady, }}, \\
\%\end{array}$ & $\begin{array}{c}\tau_{\text {closed, }}, \\
\mathrm{s}\end{array}$ & $\begin{array}{c}\tau_{\text {opened, }}, \\
\mathrm{s}\end{array}$ & $\begin{array}{c}N_{\text {cycles }}, \\
\text { cycles per } \\
\text { hour }\end{array}$ & $\eta$ \\
\hline 1 & 360 & 120 & 800 & 100 & 4 & -20.6 \\
\hline 2 & 360 & 120 & 1,600 & 200 & 2 & 6.5 \\
\hline 3 & 360 & 120 & 3,200 & 400 & 1 & 14.0 \\
\hline 4 & 540 & 180 & 800 & 100 & 4 & -24.4 \\
\hline 5 & 540 & 180 & 1,600 & 200 & 2 & -16.5 \\
\hline 6 & 540 & 180 & 3,200 & 400 & 1 & -1.8 \\
\hline 7 & 720 & 240 & 800 & 100 & 4 & -35.7 \\
\hline 8 & 720 & 240 & 1,600 & 200 & 2 & -23.7 \\
\hline 9 & 720 & 240 & 3,200 & 400 & 1 & -5.6 \\
\hline
\end{tabular}

As it can be seen from Table 1, only two of the nine options of short-term ventilation (№ 2 and № 3) are less energy consuming compared with trickle ventilation. The main attributes of options № 2 and № 3 are their relatively low heat capacity $N_{\text {rad }} / N_{\text {steady }}=130 \%$ of radiator and large ventilation periods of time $\tau_{\text {opened. }}$.

Fig. 2 shows that for option №1 due to small quantities $N_{\text {rad }} / N_{\text {steady }}=130 \%$ and high ventilation frequency (4 cycles per hour) overheating is minimal compared to the trickle ventilation while the radiator works $3,200 \mathrm{~s} / \mathrm{h}$, so more energy is spent on room heating in comparison with options №2 and №3 during which the summary heating time is respectively $2,500 \mathrm{~s} / \mathrm{h}$ and $2,100 \mathrm{~s} / \mathrm{h}$.

So according to Table 1, the short-term ventilation of short duration with a high frequency is not beneficial in terms of energy efficiency (see options № 1 and № 4 -9). Options 6 and 9 , which have a small negative value of variable $\eta$, can also achieve a positive value if the time duration $\tau_{\text {opened }}$ is decreased by enlarging the vent opening.

It should be noted that all considered variants of short-term ventilation contribute to deteriorated comfort conditions compared with the case of trickle ventilation, as the air temperature in these cases fluctuates with large amplitude (3-6 ${ }^{\circ} \mathrm{C}$ ) for $15-30$ minutes.

\section{DEVELOPMENT OF RECOMMENDATIONS}

Summarizing the obtained results, it can be concluded that in order to obtain energy efficient short-term ventilation, it has to be performed in such a way that during one window opening the entire volume of air in the room must be replaced as soon as possible.

On the other hand, if short-term ventilation lasts longer than necessary, the excess room cooling will occur, so the heat losses will increase. Therefore, the correct determination of the time duration $\tau^{*}$ of short-term ventilation is important. Using Bernoulli's equation time duration $\tau_{\text {opened }}$ can be expressed as:

$$
\tau_{\text {opened }}=\frac{V}{60 \cdot C \cdot S \cdot \sqrt{\frac{2 \cdot g \cdot h \cdot\left(\rho_{r}-\rho_{a m b}\right)}{\rho_{r}}}}
$$

In equation (2) all values are known except the empirical coefficient C. For its determination, a full-scale physical experiment was made. The test room is an office room with a volume of $58 \mathrm{~m}^{3}$ and an area of $23 \mathrm{~m}^{2}$. Ambient temperature at 
the time of the experiment was $2^{\circ} \mathrm{C}$. Used heaters have total heat capacity of 1,750 watts. The room temperature was measured by laboratory thermometer TLC-5, the temperature measurement error was $0.1{ }^{\circ} \mathrm{C}$. Experiment was performed in several stages. At the first stage, constant air temperature in the range of $21 \pm 0.5^{\circ} \mathrm{C}$ was maintained in the room for two and a half hours with the help of heaters. In this case, trickle ventilation by the presence of a small window vent opening was organized. It was found that in this case it is necessary to spend $0.83 \mathrm{kWh}$ for the room heating. The second stage of the experiment was conducted similarly to the first, but in this case the window was tightly closed.

It was obtained that it is necessary to spend $0.48 \mathrm{kWh}$ of heating during trickle ventilation.

Because the average temperature in the room at the first and second stages of the experiment was maintained at the same level $\left(21^{\circ} \mathrm{C}\right)$ and the ambient temperature did not change $\left(2{ }^{\circ} \mathrm{C}\right)$, the heat losses associated with the convection and radiation heat transfer in both cases were also the same. Then it is easy to show that the heat losses associated with the room ventilation through the opened window equal to $350 \mathrm{~W}$, and the air exchange rate in the first case is 1 volume of room air per hour. Then the required empirical coefficient $\mathrm{C}$ is equal to 0.09 .

The obtained semi-empirical equation (2) correlates well with the computational experiment on the developed threedimensional mathematical model of the room with an opened window (see Fig. 4) and the results of [3].

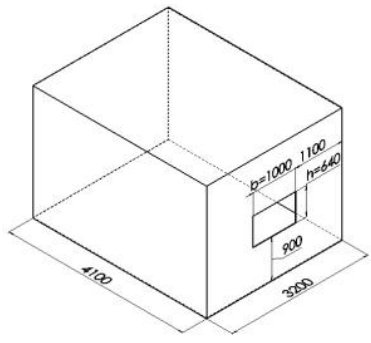

a
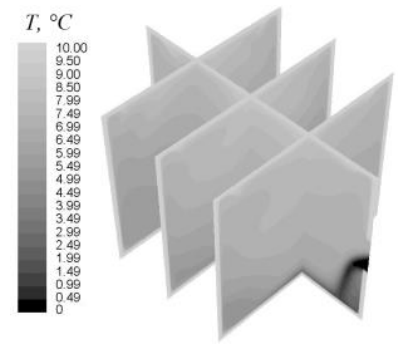

$\mathrm{b}$
Fig. 4. The results of three-dimensional CFD simulation of short-term natural ventilation. a) The geometric characteristics of the model, b) the threedimensional air room temperature field during its ventilation.

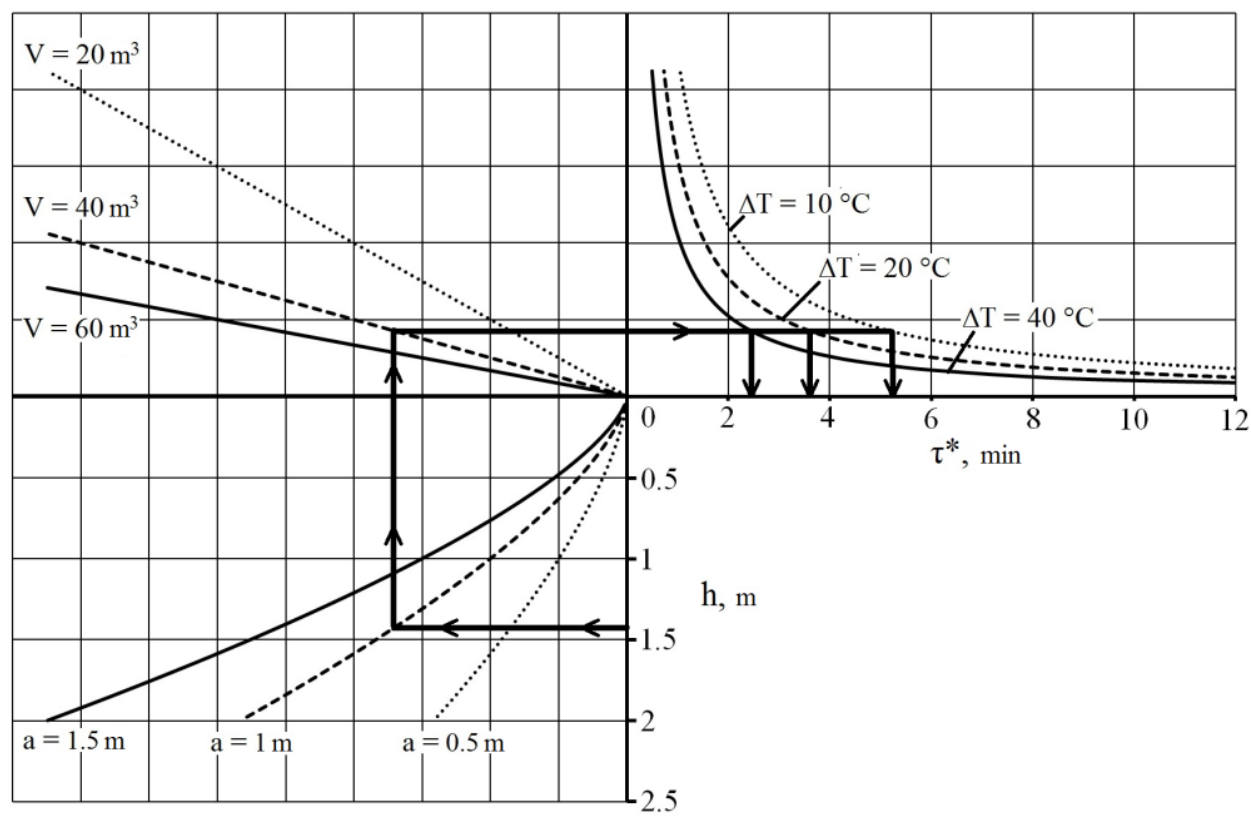

Fig. 5. Nomogram for the definition of duration of short-term ventilation.

To simplify the calculation of time duration of short-term ventilation, the nomogram was developed and is presented in Fig. 5. It is suitable for use for both office and residential premises. Nomogram allows calculating the duration of shortterm natural ventilation $\tau_{\text {opened }}$ depending on the height and area of a vent opening, room volume and the temperature difference between the room and the environment.

The known height of vent opening has to be indicated on the lower half of ordinate axis and extended to the intersection with a line, which is responsible for the width of the vent opening. Further, line rises vertically up to the intersection with the known volume of the room and to the right until it intersects the known temperature difference between the air and the environment. Then the calculated line goes vertically downwards and determines the time required for short-term ventilation. The developed nomogram is proposed for a wide range of users who will want to use the method of short-term ventilation. It should be mentioned that the duration of time between the end of the previous and the next short-term ventilation procedures is defined by the user according to the sanitary rules.

\section{DISCUSSION}

The comparison of energy efficiency of short-term natural ventilation with the trickle ventilation shows that its value can be either positive or negative depending on the frequency and intensity of short-term ventilation and the room heating capacity. The results showed that the longer the time duration 
of ventilation, the greater energy savings compared with trickle ventilation can be achieved. This is due to the fact that the temperature difference between the room and the environment during the short-term ventilation is reduced; consequently, heat losses are decreased. However, this method of ventilation creates uncomfortable conditions for persons staying indoors, so for the period of ventilation time it is recommended to leave the room. If enough time for full air exchange cannot be provided, it is recommended to use trickle ventilation instead. It also has to be admitted that the shortterm ventilation will have a greater positive effect, the lower the power of the heater will be.

In real rooms, internal heat sources (such as people, equipment, computers) are also present and this factor will increase the rate of $\eta$ relatively values given in Table 1 .

\section{CONCLUSIONS}

1. Heat losses associated with the ventilation are significant. In buildings without mechanical ventilation, energy savings can be achieved by proper managing of the natural ventilation.

2. CFD simulation of room ventilation was conducted to obtain quantitative comparison of energy efficiency of natural short-term and trickle ventilation. It was shown that the highest energy efficiency of short-term ventilation (14\%) is achieved, if it is carried out at most short period of time during which the maximum area of the window is opened for a quick complete air change in the room.

3. For the implementation of the recommendations, the nomogram has been proposed. It allows determining the optimal time duration of short-term ventilation depending on the height and area of vent opening, room volume and the temperature difference between the room air and the environment. The nomogram is based on semi-empirical dependence found from the full-scale physical experiment.

\section{REFERENCES}

[1] J. Paul and J.P.G.V. Santos, "Small heat pumps for ventilated houses and domestic hot water production," 8th IIR Gustav Lorentzen Conference on Natural Working Fluids, Copenhagen, Denmark, 2008.

[2] H. Künzel, Richtiges Heizenund Lüftenin Wohnungen. Fraunhover IRB: Verlag, 2008.

[3] P. Heiselberg and M. Perino, "Short-term airing by natural ventilation implication on IAQ and thermalcomfort," in Indoor Air, Vol. 9, 2009, pp. $126-140$

[4] R. Galvin, "Impediment energy-efficient ventilation of German dwellings: A case study in Aachen," in Energy and Buildings, Vol. 56, 2013, pp. 32-40.

[5] Ukrainian State Research Institute of Building Constructions, "Construction of buildings. Thermal insulation of buildings", Ukrainian Building Standard C.2.6-31, 2006.

[6] Swedish Standards Institute, "Thermal performance and energy use in the built environment," ISO/TC 163, 1975. 